\title{
Dysfunctional Coping Mediates the Relationship between Stress and Mental Health in Health-Care Staff Working amid the COVID-19 Pandemic
}

\author{
Katarzyna Warchoł-Biedermanna Przemysław Daroszewski ${ }^{b}$ Grażyna Bączyk ${ }^{c}$ \\ Krzysztof Greberskid, e Paweł Bugajskid, e Jacek Karońf \\ Ewa Mojs $^{\mathrm{a}}$ Michał Ziarko ${ }^{\mathrm{g}}$ Aleksandra Jasielskag ${ }^{\mathrm{W}}$ Wodzimierz Samborski ${ }^{\mathrm{h}}$ \\ aDepartment of Clinical Psychology, Poznan University of Medical Sciences, Poznań, Poland; ${ }^{\text {b}}$ Department of \\ Organization and Management in Health Care, Poznan University of Medical Sciences, Poznań, Poland; \\ 'The Department of Practice Nursing, Poznan University of Medical Sciences, Poznań, Poland; 'Department of \\ Cardiovascular Disease Prevention, Poznan University of Medical Sciences, Poznań, Poland; 'Department of Cardiac \\ Surgery Józef Strus Hospital, Poznań, Poland; fDepartment of General and Colorectal Surgery Józef Strus Hospital, \\ Poznań, Poland; '9Faculty of Psychology and Cognitive Sciences (FPCS AMU), Adam Mickiewicz University, Poznań, \\ Poland; ' Department of Rheumatology and Rehabilitation, Poznan University of Medical Sciences, Poznań, Poland
}

\section{Highlights of the Study}

- The study assesses the stress outcomes in medical staff working during the COVID-19 pandemic.

- The study explores the mediating role of coping in the relationship between stress, alexithymia, emotional processing loneliness and positive/negative affect.

- Nurses and paramedics report significantly higher stress levels than physicians.

- A positive and significant relationship was observed between stress, alexithymia, emotional processing loneliness and positive/negative affect.

\section{Keywords}

Coronavirus (2019-nCoV) · Health-care worker · Pandemic · Psychological stress

\begin{abstract}
Objective: This cross-sectional study aimed to assess the stress outcomes in health-care staff working during the $\mathrm{CO}$ VID-19 pandemic and to explore the role of coping in the relationship between stress outcomes and mental health dimensions with Preacher \& Hayes's mediation analysis. Subjects and Methods: One hundred seventy participants in-
\end{abstract}

karger@karger.com www.karger.com/mpp

Karger $\stackrel{\text { ' }}{5}$

BOPEN ACCESS
(C) 2021 The Author(s)

Published by S. Karger AG, Basel

This is an Open Access article licensed under the Creative Common Attribution-NonCommercial-4.0 International License (CC BY-NC) (http://www.karger.com/Services/OpenAccessLicense), applicable to the online version of the article only. Usage and distribution for commercial purposes requires written permission. cluding physicians ( $n=41 ; 24.1 \%$ ), nurses ( $n=114,67.1 \%$ ), and paramedics $(n=15,8.8 \%)$ with a mean age of $37.69 \pm$ 12.23 years and an average seniority of $14.40 \pm 12.32$ years were administered the Toronto Alexithymia Scale-20, Cohen's Perceived Stress Scale (PSS-10), the Emotional Processing Scale, and Positive and Negative Affect Schedule. The data were analyzed by estimation of simple correlation coefficients and a Preacher and Hayes's mediation procedure. Results: Participants reported elevated levels of stress (7-8 sten on the sten scale developed for the PSS-10 questionnaire). Statistically significant differences in the stress levels between nurses, paramedics, and physicians could not be 
determined. In contrast, significant association between mental health outcomes and the occupational category could not be found. Conclusion: Our observations support the assumption about a controlling role of coping in the relationship between work-related stress, alexithymia, emotional processing loneliness and positive/negative affect in medical staff working amid pandemic.

(C) 2021 The Author(s)

Published by S. Karger AG, Basel

\section{Introduction}

In early 2020, the World Health Organization announced a pandemic of 2019-nCoV (COVID-19, coronavirus disease). The outbreak of coronavirus disease constitutes a major public health concern. The ongoing pandemic situation has a significant impact on many aspects of the health-care system and health service providers' work worldwide [1].

There exists a considerable body of literature on specific psychological stressors affecting health-care workers (HCWs) during the COVID-19 pandemic [1-6]. First, HCW sexperience significant distress because COVID-19 is a possibly fatal communicable disease whose transmission routes are not fully understood and recommended treatments options are sparse. HCWs have an increased risk to COVID-19 infection because they are likely to contact affected individuals. Currently, limiting the exposure to infection is considered the main measure of prevention. HCWs rely on hygiene measures such as using barrier precautions to protect themselves and their patients from being infected or infecting others. Simultaneously, there are disruptions to supply of personal protection equipment, and prolonged use of specialized protective clothing can increase discomfort or lead to fatigue. Also, the effectiveness of protection equipment in preventing the dissemination of the virus can be limited. Health-care staff may also encounter stigmatizing attitudes or discrimination due to the fear of transmission of infectious diseases in the public. Frequent work overloads or prolonged work shifts due to health-care staffing shortages may result in extreme tiredness and exhaustion, poor job performance, and decreased job satisfaction. Consequently, HCWs experience moral and existential conflicts because of their inability to provide appropriate care to all their patients or feel helpless when dealing with critically ill patients. Health-care personnel find it challenging to communicate efficiently with aggressive, noncompliant, and uncooperative patients who are not adhering to COVID-19 safety instructions. Additional stressors sur- rounding the current bio-threat include isolation and working amid intense media and public coverage.

Researchers believe the current pandemic may have a lasting influence on mental health of medical staff. Yahya et al. [6] emphasized that prolonged job distress may result in adverse health consequences such as professional burnout leading to increased staff turnover and compromised quality of care. The ongoing outbreak of COVID-19 was shown to affect the well-being of all medical workers, a significant proportion of whom manifested psychosomatic symptoms of vicarious traumatization such as physical decline, inability to focus and sustain attention, sleep disturbances, or despair [3]. Middle-level nurses working in the front line and in high-risk COVID-19 areas were reported to have an increased risk of developing adverse mental health outcomes such as depression, anxiety, insomnia, and distress [4]. These studies expand our understanding of mental health outcomes of clinical work during epidemics; however, there is a dearth of knowledge on the relationship between stress, coping, and positive/negative affect, emotional processing, and alexithymia in health-care staff working at the time of the pandemic.

Previous research indicated coping styles may directly or indirectly affect mental and occupational health outcomes in medical staff $[7,8]$. Task- and emotion-oriented coping styles have been described as mediating the association between temperamental traits and occupational burnout in nurses [9], and the association between burnout and the symptoms of anxiety in physicians was shown to be partially mediated by positive and negative coping [7]. Similarly, Wang and Wang [10] demonstrated that coping styles mediated the relationship between perceived stress and mental health outcomes in physicians.

In this study, we assessed the association between alexithymia, described as impaired ability to process one's own or other's verbal and nonverbal emotional stimuli, and stress responses of HCWs working at the time of the pandemic. Research demonstrates that alexithymia is an important mental health outcome associated with insomnia and increased risk of depression, which often leads to social and occupational disability. Moreover, alexithymia has been linked to suicidal ideation and suicidal behavior $[11,12]$. In this context, it is of much interest to explore the role of these mental health dimensions in the time of the current pandemic. Understanding the psychological impact of the pandemic on health-care workers plays a pivotal role in planning for future outbreaks of emerging infectious diseases [13]. Therefore, the aim of this study was to assess the levels of stress in health-care staff working in Poland during the pandemic and to explore the role 
Table 1. Descriptive statistics of stress and mental health outcomes

\begin{tabular}{|c|c|c|c|c|c|c|c|}
\hline \multirow[t]{2}{*}{ Variable } & \multirow[t]{2}{*}{ Min } & \multirow[t]{2}{*}{ Max } & \multirow[t]{2}{*}{ M } & \multirow[t]{2}{*}{ SD } & \multirow[t]{2}{*}{ Cronbach $\alpha$} & \multicolumn{2}{|c|}{ Kolmogorov-Smirnov $Z$ test } \\
\hline & & & & & & $Z$ & $p$ value \\
\hline Stress & 0.00 & 36.00 & 19.72 & 6.97 & 0.87 & 0.068 & 0.052 \\
\hline Alexithymia & 24.00 & 81.00 & 48.46 & 12.53 & 0.83 & 0.074 & 0.026 \\
\hline Emotional processing & 10.00 & 225.00 & 89.59 & 45.60 & 0.95 & 0.104 & $<0.001$ \\
\hline Loneliness & 15.00 & 55.00 & 40.79 & 7.78 & 0.85 & 0.072 & 0.033 \\
\hline Positive affect & 10.00 & 45.00 & 31.56 & 6.92 & 0.85 & 0.063 & 0.091 \\
\hline Negative affect & 10.00 & 55.00 & 25.38 & 9.05 & 0.84 & 0.056 & 0.200 \\
\hline
\end{tabular}

of coping in the relationship between stress outcomes and mental health dimensions such as alexithymia, positive/ negative effects, emotional processing, and alexithymia using mediation analysis [14], providing a more functional knowledge of the relationships among variables. We hypothesized that coping is a mediating factor in the relationship between stress levels and mental health.

\section{Material and Methods}

\section{Participants}

This cross-sectional study was carried out during the first wave of COVID-19 pandemic (between March and June 2020) in a sample of health-care workers, who worked at COVID-19 hospital wards. Participants were recruited by convenience sampling, snowball sampling, random sampling, and word of mouth. Out of 190 subjects who were approached, eleven individuals refused to participate, 5 respondents who initially enrolled withdrew from the study, while 4 subjects returned incomplete questionnaires; the response rate was $89.4 \%$, which resulted in a sample of 170 HCWs. The sample included 170 currently employed full-time medical workers including physicians $(n=41 ; 24.1 \%)$, nurses $(n=114$, $67.1 \%)$, and paramedics $(n=15,8.8 \%)$ with an average age of 37.69 \pm 12.23 years and an average seniority of $14.40 \pm 12.32$ years. Most subjects were females $(n=142,83.5 \%)$. Each subject was informed about the purpose and importance of the study, assured of their anonymity and confidentiality, and voluntarily gave their verbal consent to participate. The investigator also made sure subjects knew they could leave the study at any moment. Ethics approval was obtained from the University's Bioethical Committee. The study was conducted in accordance with the Declaration of Helsinki, and the protocol was approved by the University's Bioethics Committee.

\section{Measures}

Subjects completed the following self-administered questionnaires.

The Toronto Alexithymia Scale-20

The scale for the assessment alexithymia consists of 20 items in 3 subscales, measuring difficulty in describing feelings (e.g., "It's difficult for me to find the right words for my feelings"); difficulty in identifying feelings (e.g., "I am often confused about what emotion I am feeling."), and an operational, externally oriented style of thinking (e.g." "I prefer talking to people about their daily activities rather than their feelings."). Subjects responded to statements using a 5-point Likert scale ranging from 1 ("totally disagree") to 5 ("totally agree") [15]. De Jong Gierveld Loneliness Scale (DJGLS) consists of 11 items indicating emotional, and social loneliness. The score reflects overall feelings of loneliness [16].

\section{Cohen's Perceived Stress Scale (PSS-10)}

This scale assesses subjects' stress levels in the past month. It consists of 10 test items in 2 subscales that measure perceived helplessness and perceived self-efficacy [17].

The Emotional Processing Scale

This scale measures emotional processing and consists of 25 items in 5 subscales as follows: (1) suppression; (2) signs of unprocessed emotion; (3) controllability of emotion; (4) avoidance; and (5) emotional experience. Subjects rated their agreement/disagreement with the statements on a 9-point scale ranging from 0 (totally disagree) to 9 (totally agree) (e.g., "My emotions felt blunt/ dull") $[18,19]$.

\section{Positive and Negative Affect Schedule}

The Positive and Negative Affect Schedule scale assesses the propensity to experience the world in a more positive or a more negative way. The questionnaire contains 20 adjectives in two 10item domains, measuring positive and negative affects (e.g., interested, excited and strong, guilty, and hostile). Subjects rate each item on a 5-point scale of 1 (not at all) to 5 (very much) $[20,21]$.

The data were analyzed in 4 steps. First, stress and mental health outcomes were compared with the reference values [15-21]. Then, simple correlation coefficients between stress levels and mental health outcomes were calculated. Additionally, Spearman's $\rho$ correlation coefficient was estimated because the analyzed variables were non-normally distributed. In step 3, the regression equation with mental health (a dependent variable) and stress levels, problem-focused, emotion-focused, and dysfunctional coping (independent variables) was designed and solved. In step 4, mediation analysis was performed as recommended by Preacher and Hayes [14] to test the hypothesis about the mediating role of coping in the relationship between stress levels and mental health. Then, the mediation analysis involving a resampling procedure with 5,000 repetitions was performed. 
Table 2. Correlation matrix of Spearman's rank correlation coefficients (rho)

\begin{tabular}{|c|c|c|c|c|c|}
\hline & 1 & 2 & 3 & 4 & 5 \\
\hline \multicolumn{6}{|l|}{ Stress } \\
\hline Alexithymia & $0.50^{* *}$ & & & & \\
\hline Emotional processing & $0.71^{* *}$ & $0.54^{* *}$ & & & \\
\hline Loneliness & $-0.50^{* *}$ & $-0.42^{* *}$ & $-0.47^{* *}$ & & \\
\hline Positive affect & $-0.44^{* *}$ & $-0.23^{* *}$ & $-0.30 * *$ & $0.33^{* *}$ & \\
\hline Negative affect & $0.77^{*}$ & $0.54^{* *}$ & $0.68^{* *}$ & $-0.48^{* *}$ & $-0.26^{* *}$ \\
\hline
\end{tabular}

Table 3. Mental health predictors

\begin{tabular}{lllr}
\hline Predictor & \multicolumn{2}{l}{ Positive affect } & \\
\cline { 2 - 4 } & $\beta$ & $T$ & $p$ value \\
\hline Stress & 0.185 & 27.665 & $<0.001$ \\
& $R^{2}=0.185, F=38.081^{* *}$ & & \\
\hline Predictor & Negative affect & & \\
\cline { 2 - 4 } & $\beta$ & $T$ & $p$ value \\
\hline Stress & 0.499 & 7.710 & $<0.001$ \\
Alexithymia & 0.199 & 3.533 & 0.001 \\
Emotional processing & 0.229 & 3.310 & 0.001 \\
& $R^{2}=0.639, F=98.028^{* *}$ & & \\
\hline
\end{tabular}

The results of stepwise regression.

Upon conducting power analyses with G*Power 3.1 [22] with up to 4 predictors in a linear multiple regression model, a sample size of 159 was deemed appropriate to detect effects of size of 0.05 or higher with an alpha of 0.05 and power of 0.80 . We recruited additional participants to account for missing data.

\section{Results}

Overall, health-care workers participating in the study reported high levels of self-rated stress on average ( 8 sten on the sten scale developed for the Cohen's Perceived Stress Scale [PSS-10] questionnaire) [17] (Table 1). Nurses experienced highest levels of stress corresponding to 8 sten $(M=24.28 ; \mathrm{SD}=4.69)$. Physicians, in turn, obtained lower PSS-10 scores, and their sten score was $7(M=$ 22.02 ; $\mathrm{SD}=4.24)$, while an average sten score in the subgroup of paramedics reached $8(M=22.67 ; \mathrm{SD}=3.8769)$ $(F=4.071[2,167] ; p=0.019)$.
Descriptive statistics of stress and mental health outcomes are presented in Table 1. The average scores reached 8 sten $(M=6.32 ; \mathrm{SD}=6.32)$. Significant statistical differences in mental health outcomes between nurses $(M=6.69 ; \mathrm{SD}=6.26 ; 8$ sten $)$, doctors $(M=5.56 ; \mathrm{SD}=5.74$; 8 sten $)$, and paramedics $(M=5.6 ; \mathrm{SD}=8.30 ; 8$ sten $)$ could not be found $(F=0.588[2,167] ; p=0.556)$.

Correlation matrix of Spearman's rank correlation coefficients (rho) is presented in Table 2. Mental health predictors and the results of stepwise regression are presented in Table 3. We found that stress mediated between problem-focused and emotion-focused coping and mental health outcomes, but the mediating effect of stress was most significant in the relationship between dysfunctional coping strategies and mental health outcomes.

\section{Discussion}

COVID-19 is a highly contagious and life-threatening viral disease. The current wave of the disease has resulted in a major pandemic affecting a significant proportion of the world's population. The ongoing pandemic has a significant impact on the entire health-care system and health-care workers worldwide. The present study focused on (i) assessing the levels of stress in medical professionals working in Poland, providing care to patients during the first wave of COVID-19 and (ii) exploring the role of coping in the relationship between stress outcomes and mental health dimensions, using mediation analysis developed by Preacher and Hayes [14].

The sample of health workers participating in the study reported significant levels of distress. Nurses and paramedics obtained test scores suggesting very high average levels of perceived stress (8 sten on the PSS-10 questionnaire sten scale). The mean results in the subgroup of physicians (7 sten on the PSS-10 questionnaire 
sten scale) may also be considered elevated, but they were significantly lower than in nurses and paramedics. These results appear to be consistent with the outcomes reported in the literature [23] and current investigations [2-6], demonstrating that nurses working amidst the wave of viral diseases encounter severe psychological strain. Schechter's team [24] observed that nurses working in the wake of COVID-19 were significantly more likely than attending physicians to manifest symptoms of acute stress. Lai and coworkers [2] demonstrated intermediate level health-care professionals such as nurses reported experiencing significantly greater distress than physicians. Similarly, Li et al. [3] reported that nonfrontline nurses had high vicarious traumatization scores, thus indicating their vulnerability to the emotional impact of coronavirus. Interestingly, nurses who were not directly combating COVID-19 were characterized by higher level of psychological strain than frontline nurses.

To our knowledge, this is the first study to examine the mediating effect of coping in the relationship between stress (an independent variable) and mental health outcomes (a dependent variable) in a sample of health-care professionals working amid the COVID-19 pandemic. Coping was observed to mediate the relationship between coping strategies and mental health outcomes. The findings indicated a negative albeit insignificant relationship between stress, coping strategies, and mental health for problem-oriented and emotion-oriented coping. In contrast, a positive and significant relationship was observed between stress, dysfunctional coping strategies, and mental health. Of note, Gershon etal. [25] demonstrated that workers who used negative or avoidant coping mechanisms reported both higher levels of perceived work stress and adverse health outcomes.

Perceived occupational stress has been reported to mediate the relationship between work characteristics and mental health outcomes. In addition, negative work characteristics, lower levels of positive work factors and work support, and emotion-focused coping styles were found to be associated with compromised mental health status [26].

The results of research on psychological determinants of health-care staff distress during a current outbreak of infectious disease should be considered in preparation of accurate prevention and support programs to prevent burnout and decreased quality of life in HCWs. Studies suggest telehealth and telemedicine services (e.g., online patient assessment or medical appointments) used worldwide as a compromise strategy to maintain patient-pro-

Coping and Mental Health - Health-Care

Staff amid COVID-19 Pandemic vider continuity amid pandemics. This may decrease staff distress by reducing the risk of transmitting the virus [27, 28].

The present study has some limitations that should be considered while interpreting the results. First, the study is based on self-reported measures. Second, there is a gender imbalance due to a higher proportion of female subjects in the sample, and this might preclude its use in any variable analysis of gender differences. However, the gender representation in the sample reflects a wellknown phenomenon of increasing numbers of women workers in health care are moving into occupations where they used to be underrepresented [29]. According to health workforce statistics, women make up $70 \%$ of health-care staff, accounting for the majority of nurses and to a lesser extent, physicians working in Poland [30]. Third, the size of our sample was relatively small but it was deemed appropriate to detect effects of a size of 0.05 or higher with an alpha of 0.05 and power of 0.80 . The fact that we were able to obtain significant differences in spite of a relatively small sample provides support for our results, but basing our study in larger sample size could have generated more accurate results. Despite these acknowledged limitations, our research has strengths in showing how coping may indirectly affect mental health outcomes in health-care personnel working at the time of the pandemic.

\section{Conclusion}

The findings of the study may improve our understanding of how health-care staff respond to and cope with dangers of global bio-threat and promote better understanding of the needs of health-care workers during the pandemic. They can also be used to boost the effectiveness of psychological interventions to maintain the well-being of health-care workers during pandemic. The well-being and emotional resiliency of health-care staff could be essential for maintaining high-quality healthcare services during the COVID-19 pandemic.

\section{Statement of Ethics}

Each subject was informed about the purpose and importance of the study, assured of their anonymity and confidentiality and voluntarily gave their verbal consent to participate. Subject's consent was not recorded to maintain their anonymity. The investigators also made sure the subjects knew they could discontinue the testing at any moment. 


\section{Conflict of Interest Statement}

The authors have no conflict of interest to declare.

\section{Author Contribution}

All authors contributed to the design and implementation of the research, to the analysis of the results, and to the writing of the manuscript.

\section{References}

1 World Health Organization. Statement on the second meeting of the International Health Regulations (2005) Emergency Committee regarding the outbreak of novel coronavirus (2019-nCoV). Geneva: WHO; 2020. Available from: https://www.who.int/newsroom/detail/30-01-2020-statement-on-thesecond-meeting-of-the-internationalhealth-regulations-(2005)-emergency-committee-regarding-the-outbreak-of-novelcoronavirus-(2019-ncov) Accessed April 15, 2020.

2 Lai J, Ma S, Wang Y, Cai Z, Hu J, Wei N, et al. Factors associated with mental health outcomes among health care workers exposed to coronavirus disease 2019. JAMA Netw Open. 2020;3(3):e203976.

3 Li Z, Ge J, Yang M, Feng J, Qiao M, Jiang R, et al. Vicarious traumatization in the general public, members, and non-members of medical teams aiding in COVID-19 control. Brain Behav Immun. 2020;88(20):916-9.

4 Montemurro N. The emotional impact of COVID-19: from medical staff to common people. Brain Behav Immun. 2020;87:23-4.

5 Tsamakis K, Triantafyllis S, Tsiptsios D, Spartalis E, Mueller C, Tsamakis C, et al. COVID-19 related stress exacerbates common physical and mental pathologies and affects treatment (review). Exp Ther Med. 2020; 20(1):159-62.A

6 Yahya AS, Khawaja S, Chukwuma J. Staff morale and well-being during the COVID-19 pandemic. Prim Care Companion CNS Disord. 2020;22(3):20com02645.

7 Ding Y, Yang Y, Yang X, Zhang T, Qiu X, He $\mathrm{X}$, et al. The mediating role of coping style in the relationship between psychological capital and burnout among Chinese nurses. PLoS One. 2015;10(4):e0122128.

8 Brudek P, Steuden SJ, Ciuła G. The mediating role of types of coping styles in the relations between temperamental traits and staff burnout among psychiatric nurses. Psychiatr Pol. 2019;53(5):1151-68.

9 Zhou J, Yang Y, Qiu X, Yang X, Pan H, Ban B, et al. Relationship between anxiety and burnout among Chinese physicians: a moderated mediation model. PLoS One. 2016;11(8): e0157013.
10 Wang Y, Wang P. Perceived stress and psychological distress among Chinese physicians: the mediating role of coping style. Medicine. 2019;98(23):e15950.

11 Hemming L, Taylor P, Haddock G, Shaw J, Pratt D. A systematic review and meta-analysis of the association between alexithymia and suicide ideation and behaviour. J Affect Disord. 2019;254:34-48.

12 Bratis D, Spanopoulou A, Dumitru S, Lagou S, Lagou S, Diamandi C, Tselebis A, et al. Sleep disturbance symptoms and their associations with alexithymia, depression and anxiety. Ann Gen Psychiatry. 2010;9(S1): 163.

13 Zaka A, Shamloo SE, Fiorente P, Tafuri A. COVID-19 pandemic as a watershed moment: a call for systematic psychological health care for frontline medical staff. J Health Psychol. 2020;25(7):883-7.

14 Preacher KJ, Hayes AF. Asymptotic and resampling strategies for assessing and comparing indirect effects in multiple mediator models. Behav Res Methods. 2008;40(3): 879-91.

15 Bagby RM, Parker JD, Taylor GJ. The twentyitem Toronto Alexithymia Scale-I. Item selection and cross-validation of the factor structure. J Psychosom Res. 1994;38(1):2332.

16 Grygiel P, Humenny G, Rebisz S, Świtaj P, Sikorska-Grygiel J. Validating the Polish adaptation of the 11-item De Jong Gierveld Loneliness Scale. Eur J Psychol Assess. 2012; 29:129-39. https://doi.org/10.1027/1015-5759/ a000130.

17 Juczyński Z, Ogińska-Bulik N. Measures of stress and coping. Warszawa: Pracownia Testów Psychologicznych; 2009

18 Baker R, Thomas S, Thomas PW, Gower P, Santonastaso M, Whittlesea A. The emotional processing scale: scale refinement and abridgement (EPS-25). J Psychosom Res. 2010;68(1):83-8.

19 Jasielska A, Górska D. Comparison of emotional processing in populations of Polish and English students - a report. Psychological Studies. 2013;51(4):5-13.

20 Crawford JR, Henry JD. The positive and negative affect schedule (PANAS): construct validity, measurement properties and normative data in a large non-clinical sample. $\mathrm{Br} \mathrm{J}$ Clin Psychol. 2004;43(Pt 3):245-65.
21 Watson D, Clark LA, Tellegen A. Development and validation of brief measures of positive and negative affect: the PANAS scales. J Pers Soc Psychol. 1988;54(6):1063-70.

22 Faul F, Erdfelder E, Buchner A, Lang AG. Statistical power analyses using $G^{*}$ Power 3.1: tests for correlation and regression analyses. Behav Res Methods. 2009;41(4):1149-60.

23 Mitchell A, Cummins T, Spearing N, Adams J, Gilroy L. Nurses' experience with vancomycin-resistant enterococci (VRE). J Clin Nurs. 2002;11(1):126-33.

24 Shechter A, Diaz F, Moise N, Anstey E, Ye S, Agarwal S, et al. Psychological distress, coping behaviors, and preferences for support among New York healthcare workers during the COVID-19 pandemic. Gen Hosp Psychiatry. 2020;66:1-8.

25 Gershon RRM, Barocas B, Canton AN, Xianbin Li LX, Vlahov D. Mental, physical, and behavioral outcomes associated with perceived work stress in police officers. Crim Justice Behav. 2008;36(3):275-89.

26 Nelson KV, Smith AP. Occupational stress, coping and mental health in Jamaican police officers. Occup Med. 2016;66(6):488-91.

27 Buonsenso D, Valentini P, Moscato U, Ricciardi W, Roland D. A pediatric strategy for the next phase of the SARS-CoV-2 pandemic. Front Pediatr. 2020;8:582798.

28 Montemurro N, Perrini P. Will COVID-19 change neurosurgical clinical practice? Br J Neurosurg. 2020:1-2.

29 Shannon G, Minckas N, Tan D, HaghparastBidgoli $\mathrm{H}$, Batura N, Mannell J. Feminisation of the health workforce and wage conditions of health professions: an exploratory analysis (published correction appears in Hum Resour Health. 2019 Nov 15;17(1):84). Hum Resour Health. 2019;17(1):72.

30 Central Statistical Office of the Republic of Poland (2017). Health and Health Care in 2016: Statistical Information and Elaborations. Central Statistical Office, Warsaw. The publication of Polish Central Statistical Office retrieved on June 16, 2020. Available from: https://stat.gov.pl/files/gfx/portalinformacyjny/pl/defaultaktualnosci/5513/1/7/1/ zdrowie_i_ochrona_zdrowia_w_2016.pdf 